\title{
Health information technology in Nigeria: Stakeholders' perspectives of nationwide implementations and meaningful use of the emerging technology in the most populous black nation
}

\author{
Ibrahim Taiwo Adeleke 1, 2,3, *, Sunday Adesubomi Erinle ${ }^{2,4}$, Ameenah Muhammad Ndana ${ }^{5}$, \\ Tony Chuks Anamah ${ }^{1,3}$, Oluseye Abiodun Ogundele ${ }^{6}$, Danjuma Aliyu ${ }^{7}$ \\ ${ }^{1}$ Department of Health Information, Federal Medical Centre, Bida, Nigeria \\ ${ }^{2}$ Centre for Health \& Allied Researches, Bida Nigeria \\ ${ }^{3}$ Health Informatics Research Initiatives in Nigeria, Bida, Nigeria \\ ${ }^{4}$ Department of Radiology, Federal Medical Centre, Bida, Nigeria \\ ${ }^{5}$ Department of Health Information Management, College of Health Technology, Minna, Nigeria \\ ${ }^{6}$ Department of Health Records, Federal Teaching Hospital, Ido-Ekiti, Nigeria \\ ${ }^{7}$ Department of Nursing Services, Ahmadu Bello University Teaching Hospital, Zaria, Nigeria
}

\section{Email address:}

ibratadeleke_aliseyin@yahoo.com (I. T. Adeleke), sundayadesubomi@yahoo.co.uk (S. A. Erinle), meenatndana@gmail.com (A. M. Ndana), tonimah33@yahoo.com (T. C. Anamah),ogundeleoluseye@gmail.com (O. A. Ogundele), aliyudanjuma19@gmail.com (Aliyu D.)

\section{To cite this article:}

Ibrahim Taiwo Adeleke, Sunday Adesubomi Erinle, Ameenah Muhammad Ndana, Tony Chuks Anamah, Oluseye Abiodun Ogundele, Danjuma Aliyu. Health Information Technology in Nigeria: Stakeholders' Perspectives of Nationwide Implementations and Meaningful Use of the Emerging Technology in the Most Populous Black Nation. American Journal of Health Research. Special Issue: Health Information Technology in Developing Nations: Challenges and Prospects Health Information Technology.

Vol. 3, No. 1-1, 2015, pp. 17-24. doi: 10.11648/j.ajhr.s.2015030101.13

\begin{abstract}
Background: Nigeria is witnessing continuing advocacy and increase in number of individuals yearning for computerization of health information and healthcare processes. On the other hand, the Government of this most populous black nation is evolving plans and strategies for the adoption and implementation of health information technology (HIT). However, little is known about opinions of the diverse healthcare providers who would act the script of government in ensuring meaningful use of HIT in the country. Objective: This nationwide, cross-sectional study attempted to determine stakeholders' perspectives of the emerging HIT in Nigeria. Result: HIT stakeholders who gave consent $(n=233)$ at the two conferences participated in the study, $76 \%$ of whom were male professionals, mostly $(117$, $50.2 \%$ ) from tertiary healthcare institutions. It worthy of note that three of the participants came from United States of America to attend the $1^{\text {st }}$ National Conference on Health Information Technology in Nigeria. Of all participants, the majority (226, 99.1\%) opined that HIT will improve communication among healthcare providers. A similar portion $(223,98.2 \%)$ were of the opinion that HIT will facilitate prompt retrieval of patient's health records on point-of-care (POC). Nearly two-third $(139,62.6 \%)$ were optimistic of possible realization of nationwide implementations of HIT in the country by the year 2020. The results also indicate that gender, professional inclination, and place of work were important predictors of positive opinion of HIT. The three factors were associated with stakeholders' opinion that the evolving HIT is capable of improving medical care quality $(p=0.059 ; 0.000 ; 0.014)$ of the Nigerian populace. Most stakeholders $(61 \%)$ recommended that the paper-based health records should be archived post implementation of HIT. Conclusion: The Nigerian healthcare system is manned by providers and stakeholders who are quite abreast of the benefits of health information technology and are willing to embrace the technology in their workflow. This is quite reassuring and tends to prompt the healthcare decision makers to proactively formulate policies and introduce interventions to encourage nationwide acceptance of the emerging technology. Nonetheless, there is more to be done on appropriate clinical documentation in order to set a friendly pedestal for effective takeoff, successful implementations and meaningful use. Appropriate funding and financial incentives for quality improvement is recommended. In addition, the National Conference on HIT should be convened annually and a technical committee be set up to appraise future implementations.
\end{abstract}

Keywords: Computerized Physician Order Entry, Decision Support Systems, Electronic Health Records, Health Informatics, Health Information Management, Health Information Technology, Interoperability, Meaningful Use 


\section{Introduction}

Health information technology (HIT) is the application of information processing involving the deployment of computers and computing technologies for storage, retrieval, sharing, and use of health information for communication and decision making to improve healthcare quality [1]. The technologies (HITs) include electronic health records (EHRs), computerized physician order entry (CPOE), health management information systems (HMIS), clinical decision support systems (CDSS), barcoding technology for medication administration, smart infusion pumps, automated dispensing machines and other technologies deployed in the management of healthcare [2-7]. The evolution of HIT began by the mid-1980s when the Institute of Medicine (IOM) in USA identified that new technologies should be considered for improving the state of health records and healthcare systems [8]. Huffman [9] recognized that the first health related ICT applications were those requiring arithmetic applications such as registration, admission, discharge and transfer (R-ADT); census; hospital statistics; abstraction of health records and indexing. HIT applications have been reported [10] to have provided easy and instant access to vital health information capable of improving provision of quality healthcare as well as informed decision making, to healthcare professionals, planners, managers, policy makers and national health agencies.

HIT has gained increased importance since 2001 when the Institute of Medicine declared it as one measure to improve the effectiveness and timeliness of healthcare delivery and patient safety [11]. Effective application of HITs with high interoperability and process simplification hold the impetus for substantial improvement as they are widely held as primary patient safety solutions [12, 2-7]. HIT improves the quality of, and enhances access to health information, brings increased healthcare efficiency and quality and enhances health communication strategies and research [13]. It facilitates data management tasks of health administrators [10] and improves access to the patient health records to the satisfaction of clinicians [14]. It reduces medical errors through prompt alerts and reminders [10]. HIT evolution has improved the sharing and real time access to patient health information on point-of-care [10] and it is facilitating healthcare delivery reform and reshaping the work of healthcare professionals [15]. In spite of the benefits and promises of HITs, other studies have reported challenges of the technology. For instance, studies have shown that its implementations could not go without significant risks to patients and providers [16]. Cases of fatal insulin overdose as a result of mix-up in the bar-coded wristbands [17], dehumanization as providers focused computer screens in lieu of their critically ill-patients [18], incorrect medications chosen from computerized pick lists [19], and most awful, escalation of paediatric mortality subsequent to computerized system [18]. Furthermore, researchers have reported that sites where CPOE were implemented still experience high rates of medication errors and adverse drug events (ADEs) [20], errors related to entry, retrieval, communication and coordination of health information [21] and low adoption rate of HIT [22].

Of particular importance in this study is the fact that healthcare providers who are satisfied with their careers are more likely to stay in their practice and hence, care continuity is assured and care delivery enhanced. Elder et al [23] established that HIT was the strongest positive predictor of physicians' satisfaction with their careers. Adler-Milstein [24] opined that the expected efficiency and quality from HITs may become unrealistic except with change management in order to orchestrate meaningful use by both care providers and administrators. It has been said [25] that a good HIT application must not only be adopted and implemented but, must also be used in a meaningful way by providers so that the desired results such as reduced costs and improved care quality and safety are achieved. The standard of meaningful use strikes a balance between acknowledging the urgency of adopting the technologies to improve healthcare system and recognizing the challenges that may follow such implementations [26]. In the same vein, lack of systematic records management has been linked to the persistence of data corruption [27] and there is problem of inadequate health information management systems in developing nations [28]. Apparently, contemporary issues in health information management practice and healthcare systems management in Nigeria are capable of provoking the immediate adoption and implementation of HIT in order to revolutionize the moribund systems. For instance, most healthcare settings in Nigeria are predominantly on paperbased health information systems [29]; clinical documentation in the prevailing manual system has been reported to be suboptimal [30] and providers have been reported [31, 29 and 32] to lack the right computing skills relative to their responsibilities. However, other studies from Nigeria demonstrate that healthcare providers believe in the efficacy of HIT in enhancing medical confidentiality [33] and that providers now use computer and the Internet to enhance their professionalism and improve healthcare quality [34].

Over the years, the Nigerian Government developed a 5year Strategic plan on health and of the six building blocks of achieving the goals, health information system takes a strategic position. The goal is to provide an effective National Health Management Information System (NHMIS) by all the governments of the Federation to be used as a management tool for informed decision making at all levels and for improved healthcare [35]. In furtherance of her efforts to achieve the plan, the Government recognized the need to have a harmonized health information management through HIT. It was on this premise that the first National Conference on HIT was organized by the Federal Ministry of Health between November 2 and 4, 2011 (see Fig 1). The 
focus of the conference was to have one harmonized health data management system and the specific objectives were to compile a list of health information system applications in use in the country, to review the interoperability of the existing systems, to review the HIT components of the country's ehealth strategies and to propose strategies for the establishments of interoperability standards and capacity building. Subsequently, the National Council on Health in August 2013 approved the deployment of EHRs in all the thirty six states of the federation, including the Federal Capital Territory [36].

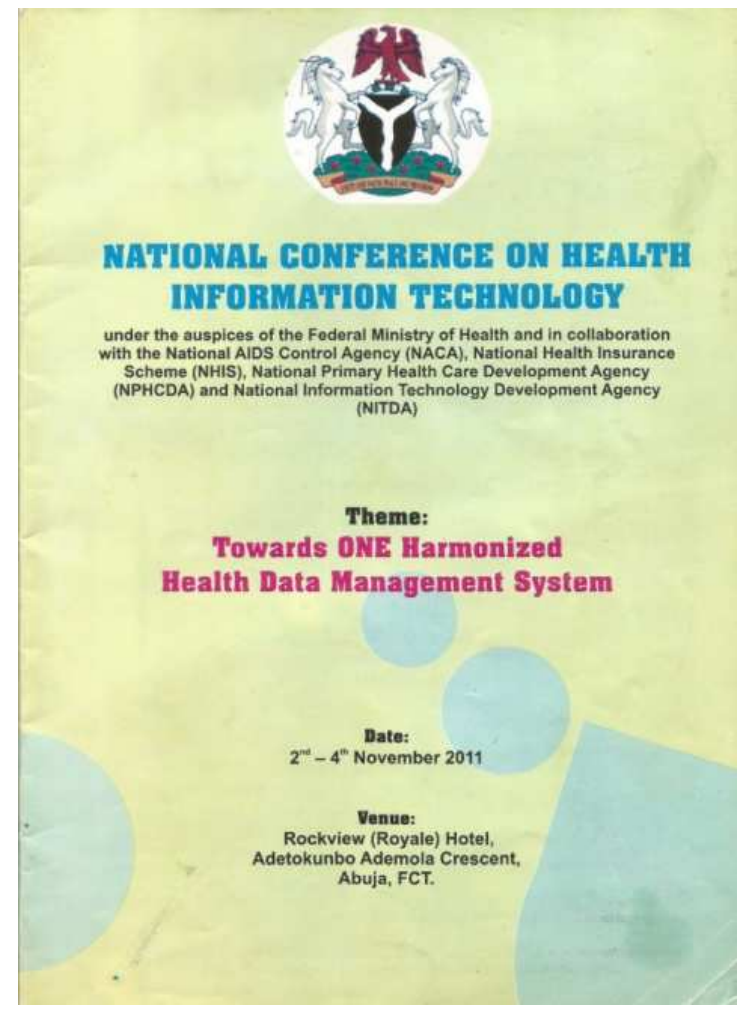

Fig 1. $1^{\text {st }}$ National Conference on HIT in Nigeria, 2011

\subsection{Aim of the Study}

The associated benefits of HIT over paper-based health records systems are widely appreciated and quite obvious. However, the Nigerian healthcare system is predominantly paper-based and stakeholders would require specific advocacy for the promotion, adoption and effective implementations of HIT for optimal use and improved healthcare quality. Therefore, this study attempted to determine the perceptions of all stakeholders towards the emerging health information technology in Nigeria.

\section{Methods}

\subsection{Background to the Study Areas}

The study was carried out at two national conferences that brought relevant healthcare providers and stakeholders together in 2011 and 2014 respectively. The first was at the maiden National Conference on Health Information
Technology organized by the Federal Ministry of Health in collaboration with some government agencies such as National AIDS Control Agency (NACA), National Health Insurance Scheme (NHIS), National Primary Health Care Development Agency (NPHCDA) and National Information Technology Development Agency (NITDA). The conference was coordinated by the Foundation for Sustainable Health Development (FSHD) at the Rockview Royale Hotel Abuja FCT. This was held between $2^{\text {nd }}$ and $4^{\text {th }}$ of November 2011. The second conference was the $15^{\text {th }}$ National Scientific Conference of the Islamic Medical Association of Nigeria (IMAN) held between $12^{\text {th }}$ and $15^{\text {th }}$ June 2014 at the Justice Idris Legbo Kutigi International Conference Centre, opposite Government House, Minna Niger State Nigeria.

\subsection{Study Design}

This is a cross-sectional survey of healthcare stakeholders on the emerging HIT.

\subsection{Study Population}

Participants in this study include healthcare professionals (such as doctors, nurses, HIM professionals and so on) and other practitioners who by the virtue of their workplace, contribute to healthcare services delivery (such as IT professionals, administrators, planners and so on).

\subsection{Data Collection Tools}

A 25-point questionnaire on the subject was administered on the conference attendees who so agreed to participate in the study.

\subsection{Sampling Techniques and Sample Size}

A convenience sample, randomly selected from the conference attendees in 2011 and 2014 was recruited for the study. A total of 233 gave their consent for participation.

\subsection{Inclusion and Exclusion Criteria}

In spite of the wide gap between the two conferences (2011 and 2014), participants were restricted only to conference attendees.

\subsection{Data analysis and Management}

The Statistical Software (SPSS 16.0 for window) was used to analyze the data. Chi square and Cramer's V were computed for the nominal by nominal variables and $p$-value for statistical significance was set at 0.05 . Simple percentage was also computed for succinct descriptions.

\subsection{Ethics}

Informed consent was clearly worded on the page before the questionnaire to obtain participants' consent. Permission to administer the instrument was granted by the head of the coordinating body (FSHD) at the $1^{\text {st }}$ National Conference on HIT in 2011 and the National Secretary of IMAN gave the pass at the second venue in Minna Nigeria. 


\section{Result}

\subsection{Participants' Profile}

Table 1. Professional inclinations of participants

\begin{tabular}{lll}
\hline & Frequency & Percent \\
\hline Health Information Management & 65 & 27.9 \\
Nursing & 41 & 17.6 \\
Information Technology & 27 & 11.6 \\
Medicine \& Surgery & 21 & 9.0 \\
Pharmacy & 11 & 4.7 \\
Medical Laboratory Science & 10 & 4.3 \\
Secretariat/Administration & 6 & 2.6 \\
Community/Environmental Health & 5 & 2.1 \\
Accounting/Banking & 4 & 1.7 \\
Others & 43 & 18.5 \\
& 233 & 100 \\
\hline
\end{tabular}

Table 2. Spread of participants' workplace

\begin{tabular}{lll}
\hline Facilities & Frequency & Percent \\
\hline Tertiary healthcare facilities & 117 & 50.2 \\
Secondary/state specialist hospitals & 30 & 12.9 \\
Non-governmental organizations & 14 & 6.0 \\
States ministry of health/hospital & 10 & 4.3 \\
management boards & 10 & 4.3 \\
Training institutions/school health centres & 7 & 3.0 \\
Primary healthcare centres & 4 & 1.7 \\
Federal Ministry of Health & 4 & 1.7 \\
Regulatory bodies/health agencies & 3 & 1.3 \\
Private organizations & 3 & 1.3 \\
Intra Health, USA & 31 & 13.3 \\
Others & 233 & 100 \\
& & \\
Geographical location of workplace & 91 & 39.1 \\
North-central, Nigeria & 53 & 22.7 \\
North-west, Nigeria & 26 & 11.2 \\
North-east, Nigeria & 21 & 9.0 \\
South-west, Nigeria & 7 & 3.0 \\
South-east, Nigeria & 3 & 1.3 \\
International partner (USA) & 1 & 0.4 \\
South-south, Nigeria & 31 & 13.3 \\
Others (location not specified) & 233 & 100 \\
\hline
\end{tabular}

At the two conferences, 233 participants completed and returned the questionnaires, $76 \%$ of whom were male professionals. Table 1 that follows shows that more than a quarter $(65,27.9 \%)$ of participants were HIM professionals. This was distantly followed by nurses $(41,17.6 \%)$ and IT practitioners $(27,11.6 \%)$. Table 2 presents participants' workplace and further illustrates geographical locations of their workplace. Half of the participants came from tertiary health institutions and it is important to note that a number (3, $1.3 \%$ ) of them came from the United State of America to the $1^{\text {st }}$ National Conference on HIT. Table 2 also shows that the spread of participants' workplace across Nigeria depicts that two in every five of the participants worked in North-central Nigeria.

\subsection{Attitude Toward Health Information Technology}

Most participants $(181,77.8 \%)$ own laptop computers and some of them $(78,43.1 \%)$ brought it to the venue of the conference while financial constrains remain the major (18, $34.6 \%)$ reason some participants could not have one. A simple majority $(159,68.2 \%)$ utilized the Internet daily while a higher portion $(171,73.4 \%)$ possess email address and nearly onefifth $(22,19.8 \%)$ of the participants came from facilities with full computerization of processes. The most frequently suggested solution or action $(107,60.8)$ to be taken on paper records in the wake of HIT is to archive them and this was distantly followed by electronic back up (30, 17.0\%).

\subsection{Participants' Opinions of the Emerging Health Information Technology}

Table 3 below shows that the majority $(226,99.1 \%)$ of participants admitted that HIT will improve communication among healthcare providers while a half of them $(114,51.6 \%)$ argued that HIT goes beyond being just a replica of the traditional medical record systems. More than two-third (151, $66.8 \%$ ) of the participants were optimistic that holistic and seamless paperless health records systems is feasible in Nigeria and nearly the same portion of them $(139,62.6 \%)$ believed that nationwide implementation of HIT is possible by the year 2020 .

Table 3. Perceptions of the emerging HIT

\begin{tabular}{|c|c|c|c|c|}
\hline & $\mathbf{N}$ & Yes/True & No/false/unsure & $\%$ in favour of HIT \\
\hline Holistic paperless health records systems is possible in Nigeria & 226 & 151 & 82 & 66.8 \\
\hline HIT will facilitate prompt retrieval of patients' health records & 227 & 223 & 4 & 98.2 \\
\hline HIT will improve communication among healthcare providers & 228 & 226 & 2 & 99.1 \\
\hline HIT will enhance confidentiality of the protected health information & 227 & 207 & 20 & 91.2 \\
\hline HIT will improve the quality of medical care & 228 & 224 & 4 & 98.2 \\
\hline HIT will save hospitals the cost of paper stationery & 229 & 216 & 13 & 94.3 \\
\hline HIT will lead to retrenchment of hospital staff & 227 & 75 & 152 & 67.0 \\
\hline HIT will dehumanize patient-doctor relationship & 220 & 48 & 172 & 78.2 \\
\hline HIT will pose threats to patient's privacy & 224 & 77 & 147 & 65.6 \\
\hline Misfiling and mislaying of patients' health records will be laid to rest in the wake of HIT & 226 & 149 & 77 & 65.9 \\
\hline HIT is the electronic replica of the traditional health records management & 221 & 107 & 114 & 51.6 \\
\hline Feasibility of HIT in Nigeria by year 2020 & 222 & 139 & 83 & 62.6 \\
\hline
\end{tabular}




\subsection{Factors Associated with Opinions on Health Information Technology}

Factors associated with participants' opinions of the emerging HIT are highlighted in Table 4. Essentially, sex, profession and workplace contributed a lot to how participants viewed the workability and the potential benefits of HIT in Nigeria. The most significantly influencing factor is sex and it is the only factor that affects participants' optimism about the feasibility of a paperless healthcare system in Nigeria $(p=0.010)$ and frequent utilization of the Internet $(p=0.001)$. All the trio of sex, profession and workplace are associated with stakeholders' opinion that the evolving HIT is capable of improving medical care quality ( $p=0.059 ; 0.000 ; 0.014$ ) of the Nigerian populace.

Table 4. Association between variables and participants' opinions of HIT

\begin{tabular}{|c|c|c|c|c|}
\hline & Chi square $(\chi 2)$ & Cramer V ( $\varphi c)$ & df* & p-value \\
\hline \multicolumn{5}{|l|}{ Sex set against opinions } \\
\hline Frequent utilization of the Internet & 19.668 & 0.291 & 4 & 0.001 \\
\hline Holistic paperless health records systems is possible in Nigeria & 11.249 & 0.220 & 3 & 0.010 \\
\hline HIT will improve the quality of medical care & 5.660 & 0.156 & 2 & 0.059 \\
\hline HIT will dehumanize patient-doctor relationship & 5.668 & 0.156 & 2 & 0.059 \\
\hline Misfiling and mislaying of patients' health records will be laid to rest in the wake of HIT & 6.242 & 0.164 & 3 & 0.100 \\
\hline Frequent utilization of the Internet & 3.633 & 0.624 & 352 & 0.327 \\
\hline Holistic paperless health records systems is possible in Nigeria & 2.824 & 0.636 & 264 & 0.209 \\
\hline HIT will enhance confidentiality of the protected health information & 2.329 & 0.707 & 176 & 0.003 \\
\hline HIT will improve the quality of medical care & 3.245 & 0.835 & 176 & 0.000 \\
\hline HIT will dehumanize patient-doctor relationship & 1.725 & 0.608 & 176 & 0.561 \\
\hline $\begin{array}{l}\text { Misfiling and mislaying of patients' health records will be laid to rest in the wake of HIT } \\
\text { Workplace set against opinions }\end{array}$ & 3.404 & 0.698 & 264 & 0.001 \\
\hline Frequent utilization of the Internet & 6.625 & 0.843 & 660 & 0.465 \\
\hline HIT will enhance confidentiality of the protected health information & 4.088 & 0.937 & 330 & 0.002 \\
\hline HIT will improve the quality of medical care & 3.889 & 0.914 & 330 & 0.014 \\
\hline HIT will dehumanize patient-doctor relationship & 3.485 & 0.865 & 330 & 0.232 \\
\hline Misfiling and mislaying of patients' health records will be laid to rest in the wake of HIT & 5.374 & 0.877 & 495 & 0.091 \\
\hline
\end{tabular}
$* \mathrm{df}=$ degree of freedom

\section{Discussion}

Health information technology otherwise known as digitization and globalization of healthcare systems has been advanced [34] to have the potentials to speed up the required transformation of the Nigerian healthcare systems and revolutionize the provider-consumer relationship. Other studies $[37,26]$ further corroborated this assertion that the use of HITs will support better care of patients; enhance decision making process and patients' outcome and subsequent meaningful use. When patients experience the gains of HITs, they will demand nothing less from their providers [26]. HIT has tremendous potentials to transform how healthcare is delivered and this present survey of the Nigerian healthcare system holds promises to achieve better care in the wake of HIT.

Many researches on HIT often focus on IT design and implementations but perhaps not on perceptions of healthcare providers whereas, there is more to HIT success than IT designs and systems procurement. In spite of the advancement and benefits of HIT, studies [38] have shown that there is little evidence pointing to the ability of healthcare providers to communicate effectively. It is feeble to assume that any use of the technology is better than no use at all [39]. This brings about the technological slogan of garbage-in-garbage-out, the fact that computer cannot operate itself [29] and the need to improve reported inadequacies in clinical documentation [30]. Meaningful use of HIT has been advocated [25-26] as against mere procurement and implementations of the technology. As such, the view and readiness of end-users of the technology therefore becomes paramount. In line with this, our study reveals a reasonable part of the stakeholders in Nigeria admitted that the technology promises to; improve communication among providers (99\%), improve medical quality (98\%), enhance medical confidentiality $(91 \%)$, not to dehumanize doctor-patient relationship (78\%), reduce misfiling and mislaying of patient's health records $(66 \%)$ and above all, $63 \%$ of them believed that nationwide implementation of HIT is possible in Nigeria by the year 2020. Though studies [40, 4] reported that HIT portends significant risks to both the care giver and the patients, outcomes of our study are analogous to reports from researchers such as Classen et al [41] and Adeleke et al [29] where the technology is seen as having potentials to improve medical care safety and quality; Adeleke et al [29] and Adeleke et al [33] establishing findings that the technology possesses the potentials to enhance medical confidentiality than paper-based health records; and Adeleke et al [29] that HIT will not dehumanize doctor-patient relationship.

The demographic patterns of participants in this study precipitate a new order compared to the situation in developed nations. In the United States of America and Australia for instance, women mostly occupy key roles in 
healthcare information systems and HIT. However, this current study shows a changing trend in responsibilities as more male $(68 \%)$ HIM professionals participated in the efforts to bring about HIT in Nigeria than their female counterparts $(32 \%)$. Generally, more male healthcare professionals participated in this effort. For instance, $73 \%$ of males as against $54 \%$ of females used the Internet frequently; $67 \%$ of males as against $60 \%$ of females were optimistic of paperless health records systems; and $97 \%$ of male as against $93 \%$ of females believed HIT will improve the quality of medical care. Statistically, sex is found to be the most associative factor to opinions on HIT. This finding on gender influence is congruent to other studies where females exhibited more negative attitudes towards computers and the Internet than men [42] and where males rather than their females had previously played online games [43].

This discovery is another breakthrough pointing to the fact that unlike their female counterparts, male healthcare providers in Nigeria go beyond just their primary professional obligations for the enhancement of their career. Earlier study [31] on research behaviour equally established that males are better than females in terms of investigative healthcare. Similarly, profession $(p=0.000)$ and workplace ( $p=0.002)$ were significantly associated with perceptions of health IT. Clear evidence of this include the use of internet with $82 \%$ of IT practitioners and $51 \%$ of HIM professionals using it daily; and positive impact of HIT on medical confidentiality with highest percentage (94\%) among HIM professionals and lowest at $70 \%$ among medical laboratory scientists. This finding goes with reports in studies such as Adeleke et al [34] and Bello et al [32] where profession was a factor on how people used computer and the Internet.

The level of preparedness for the adoption and effective implementations of HIT is encouraging as this study has shown an enormous improvement on previous studies from Nigeria. For instance, our study shows that $78 \%$ of participants possessed personal laptop computer as against $64 \%$ in Adeleke et al [29], 68\% utilized the Internet daily and $73 \%$ possessed email address as against $50 \%$ and $58 \%$ respectively, in a recent study [34]. One-fifth (20\%) of the participants as against $8 \%$ reported by Adeleke et al [29] came from facilities with full computerization of processes. More than half of the participants (52\%) agreed that HIT goes beyond being just a replica of the traditional medical record systems. Hoffman \& Podgurski [39] similarly argued that the functionality of comprehensive EHRs systems goes far beyond the traditional role of paper medical records. Statistically, possession of laptop is associated $(p=0.048)$ with the belief that HIT will improve medical care quality; frequent use of the Internet is associated with ability of HIT to facilitate prompt retrieval of patient's records $(p=0.006)$ and save cost $(p=0.000)$. Similarly, belonging to a facility with some level of computerization is associated $(p=0.000)$ with an optimism that achieving HIT by the year 2020 is realistic. Contrary to our findings, Aaronson et al [44] reported that prior experience with computer had no association with satisfaction with EHRs. However, other studies in accord with our findings elucidate that increase computer experience influenced positive attitude, and perceived usefulness of HIT among healthcare providers [40, 45-46].

Recommendations on what should be done to paper-based health records post implementation of HIT include holistic archiving for the purpose of references (61\%), electronic back up (17\%). However, a significant portion (14\%) advocated the destruction of such records in order to facilitate holistic paperless system. This calls for concern as no nation has attained $100 \%$ level of country-wide holistic paperless healthcare systems $[9,47]$. As such, opting for the destruction of paper-based health records may be inimical to meaningful use and produce negative effects on public health Intensive advocacy is therefore required reorient many Nigerian stakeholders about the emerging technology. To effectively implement HIT for a meaningful use and improved healthcare, studies [41, 48] have recommended financial incentives and eventual penalties to defaulting individual providers and health facility.

\subsection{Study Limitations}

There was a wide gap between 2011 and 2014 for the field work due to the quest to wait for another gathering of all stakeholders nationwide. This might have influenced certain improvement in attitude toward, and opinions about HIT among participants.

\section{Conclusion}

The Nigerian healthcare system is manned by providers and stakeholders who are quite abreast of the benefits of HIT and are willing to embrace the technology in their workflow. These healthcare providers exhibited readiness to adopt the technology and the government as well is positively disposed to the nationwide implementations of the emerging technology. Practically, this is quite reassuring and may prompt the healthcare decision makers to proactively formulate policies and introduce interventions to encourage nationwide acceptance of HIT. However, there is more to be done on appropriate clinical documentation in order to set a friendly pedestal for effective takeoff, successful implementations and meaningful use of the technology. For better appreciation of Government plans on HIT, the National Conference on HIT should be convened annually and a technical committee be set up to appraise future implementations.

\section{Recommendations}

i. Nationwide advocacy on the need to adopt Health IT

ii. Continuing professional and IT education for all stakeholders

iii. Establishment of clinical documentation improvement committee in health facilities, such that will ensure data quality and appropriate clinical documentation.

iv. Encouragement of local content software development 
v. Appropriate funding of the project and introduction of financial incentive to facilities that improve healthcare quality through HIT adoption, implementations and meaningful use.

\section{Acknowledgement}

The authors wish to specially thank Mr. BK Ayilegbe of the Department of Health Records, Aminu Kano Teaching Hospital, Kano for his observation on some lexical structure at the initial stage of the study. Also, Miss Blessing Ikwuta of Niger State College of Nursing Bida and Mr. AB Jimoh of the Department of Health Information, Federal Medical Centre, Bida for their participation during final proofreading of the manuscript. All the 233 participants across the nation are duly acknowledged.

\section{References}

[1] T. G. Thompson, D. J. Brailer. The decade of health information technology: delivering consumer-centric and information-rich healthcare. Framework for Strategic Action. Available www.providersedge.com/ehdocs/ehr_articles/The_Decade_of

HIT- Delivering_Customer-centric_and_Info-rich_HC.pdf Accessed on November 11, 2011.

[2] D. W. Bates, A. A. Gawande. Patient safety: improving safety with information technology. New England Journal of Medicine. 2003; 348:2526-2534.

[3] R. Kaushal, D. W. Bates. Information technology and medication safety: what is the benefit? Quality \& Safety in Healthcare, 2002;11:261-265.

[4] Institute of Medicine. To err is human: building a safer health system. Institute of Medicine Report on Medical Errors. Washington, DC: National Academies Press, 2000.

[5] Institute of Medicine. Patient safety: achieving a new standard for care. Washington, DC: National Academies Press, 2004.

[6] R. Kaushal, K. N. Barker, D. W. Bates. How can information technology improve patient safety and reduce medication errors in children's health care? Archives of Pediatrics \& Adolescent Medicine. 2001;155:1002-1007.

[7] P. Kilbridge. Crossing the chasm with information technology: bridging the quality gap in healthcare. California HealthCare Foundation, 2002.

[8] M. Amatayakul. Electronic Health Records. In: Health Information Management Technology: An Applied Approach. $\left(2^{\text {nd }}\right.$ ed.) Johns ML (Ed). American Health Information Management Association Chicago Illinois, 2007; p120.

[9] E.K. Huffman, Medical Record Management ( $9^{\text {th }}$ edition). Physicians' Records Company Berwyn Illinois. Revised by the American Health Information Management Association, 1990 p541-569.

[10] R. K. Sinha. Impact of health information technology in public health. Sri Lanka Journal of Bio-Medical Informatics 2010;1(4):223-36.

[11] Institute of Medicine (U.S.), Committee on Quality of
Healthcare in America. Crossing the quality chasm: a new health system for the 21st Century. Washington, DC: National Academy Press; 2001.

[12] D. W. Bates, M. Cohen, L. L. Leape, J. M. Overhage, M. M. Shabot, T. Sheridan. Reducing the frequency of errors in medicine using information technology. J Am Med Inform Assoc. 2001; 8(4): 299-308.

[13] D. Jackie. ICT in the health sector: literature review. InfoDev. 2006:1-7. Available at: www.asksource.info/res_library/ict.htm (Accessed on: May $17,2010)$

[14] K. Janus, V. E. Amelung, L. C. Baker, M. Gaitanides, F. W. Schwartz, T. G. Rundall. Job satisfaction and motivation among physicians in academic medical centres: insights from a cross-national study. Journal of Health Politics Policy Law. 2008;33(6):1133-67.

[15] L. Kloss. Redefining the role of health information management in the new world of information governance. Iron Mountain Incorporated, 2013.

[16] R. M. Wachter. Could computerization harm patient safety? Med Gen Med. 2006;8(2):84. PMCID: PMC1785161

[17] C. J. McDonald. Computerization can create safety hazards: a bar-coding near miss. Ann Intern Med. 2006; 144(7):510-516. doi:10.7326/0003-4819-144-7-200604040-00010.

[18] Y. Y. Han, J. A, Carcillo, S. T. Venkataraman, et al. Unexpected increased mortality after implementation of a commercially sold Computerized Physician Order Entry System. Pediatrics. 2005;116;1506. doi: 10.1542/peds.20051287.

[19] R. Koppel, J. P. Metlay, A. Cohen, et al. Role of Computerized Physician Order Entry Systems in facilitating medication errors. JAMA. 2005;293(10):1197-1203. doi:10.1001/jama.293.10.1197.

[20] T. A. Shamliyan, S. Duval, J. Du, R. L. Kane. Just what the doctor ordered. review of the evidence of the impact of Computerized Physician Order Entry system on medication errors. Health Services Research. 2008;43(1):32-53.

[21] J. S. Ash, M. Berg, E. Coiera. Some unintended consequences of information technology in healthcare: the nature of patient care information system-related errors. J Am Med Inform Assoc 2004;11:104-112 doi:10.1197/jamia.M1471.

[22] B. Karsh, M. B. Weiger, P. A. Abbott, R. L. Wears. Health information technology: fallacies and sober realities. J Am Med Inform Assoc 2010;17:617-623 doi:10.1136/jamia.2010.005637].

[23] K. T. Elder, J. C. Wilthshire, R. N. Rooks, R. BeLue, L. C. Gary. Health information technology and physician career satisfaction. Perspect Health Inf Manag. 2010 7:1d. PMC2921302.

[24] J. Adler-Milstein. Healthcare requires big changes to complement new IT. Harvard Business Review, April 2009.

[25] D. Classen, D. W. Bates, C. R. Denham. Meaningful Use of Computerized Prescriber Order Entry. J Patient Saf. 2010; 6(1):15-23. www.journalpatientsafety.com.

[26] D. Blumenthal, M. Tavenner. N The "Meaningful Use" Regulation for Electronic Health RecordsEngl J Med. 2010;363(6):501-504. 
[27] M. I. M. Salleh, R. A. R. Yaacob, M. S. M. Saleh. The effect of performance impact on the integrity management of electronic medical records. Australian Journal of Basic and Applied Sciences. 2013;7(6):237-245.

[28] M. C. Azubuike, J. E. Ehiri. Health information systems in developing countries: benefits, problems, and prospects. The Journal of the Royal Society for the Promotion of Health. 1999; 119:180. doi: 10.1177/146642409911900309.

[29] I. T. Adeleke, A. H. Lawal, R. A. Adio, A. A. Adebisi. Information technology skills and training needs of health information management professionals in Nigeria: a nationwide study. Health Information Management Journal, 2014. doi.org/10.12826/18333575.2014.0002.Adeleke.

[30] I. T. Adeleke, A. O. Adekanye, K. A. Onawola, et al. Data quality assessment in healthcare: a 365-day chart review of inpatients' health records at a Nigerian tertiary hospital. Journal of American Medical Informatics Association. 2012;19(6):1039-42. doi:10.1136/amiajnl-2012-000823.

[31] I. T. Adeleke, A. O. Adekanye, A. D. Jibril, F. F. Danmallam, H. E. Inyinbor, S. A. Omokanye. Research knowledge and behaviour of health workers at Federal Medical Centre, Bida: a task before learned mentors. El Mednifico Journal. 2014;2:2.

[32] I. S. Bello, F. A. Arogundade, A. A. Sanusi, I. T. Ezeoma, E. A Abioye-Kuteyi, A. Akinsola. Knowledge and utilization of information technology among healthcare professionals and students in Ile-Ife, Nigeria: A case study of a University Teaching Hospital. Journal of Medical Internet Research. 2004;6(4): e45.

[33] I. T. Adeleke, A. O. Adekanye, S. A. Adefemi, et al. Knowledge, attitudes and practice of confidentiality of patients' health records among healthcare professionals at Federal Medical Centre, Bida. Nigerian Journal of Medicine. 2011; 20(2): 228-235.

[34] I. T. Adeleke, M. A. Asiru, B. M. Oweghoro, A. B. Jimoh, A. M. Ndana. Computer and internet use among tertiary healthcare providers and trainees in a Nigerian public hospital. American Journal of Health Research. Special Issue: Health Information Technology in Developing Nations: Challenges and Prospects Health Information Technology. 2015; 3(6):110. doi: 10.11648/j.ajhr.s.20150306.11.

[35] Ministry of Health. National Strategic Health Development Plan (NSHDP) 2010- 2015. Nov 2010 50-51p. Available at www.NSHDP inside pages 231210 .pdf. Accessed on $4^{\text {th }}$ November $20 \overline{1}$.

[36] M. M. Ibrahim. Benefits realization of the implementation of electronic health records (EHRs) in Nigeria. In: I. T. Adeleke \& O. O. Ajayi (ed). Conference Proceedings of Health Information Managers' Association of Nigeria. HIM Connect, 2014:7-15.
[37] R. J. Baron. Meaningful Use of Health Information Technology Is Managing Information. JAMA. 2010; 304(1):89-90.

[38] C. Robert, K. Trana, V. Loa, et al. Effects of clinical communication interventions in hospitals: a systematic review of information and communication technology adoptions for improved communication between clinicians. International Journal of Medical Informatics. 2012;81:723-732.

[39] S. Hoffman, A. Podgurski. Meaningful use and certification of Health Information Technology: What about Safety? Journal of Law, Medicine \& Ethics. 2011:77-80.

[40] L. A. Huryk. Factors influencing nurses' attitudes towards healthcare information technology. Journal of Nursing Management. 2010;18(5): 606-612.

[41] D. Classen, D. W. Bates, C. R. Denham. Meaningful use of Computerized Prescriber Order Entry. J Patient Saf. 2010; 6(1):15-23. www.journalpatientsafety.com.

[42] A. Broos. Gender and information and communication technologies (ICT) anxiety: male self-assurance and female hesitation. CyberPsychology \& Behavior. 2005;8(1):21-31. doi:10.1089/cpb.2005.8.21. [Abstract]

[43] K. Chih-Hung, Y. Ju-Yu, C. Cheng-Chung, C. Sue-Huei, Y. Cheng-Fang. Gender differences and related factors affecting online gaming addiction among Taiwanese Adolescents. Journal of Nervous \& Mental Disease. 2005;193(4):273-277 [Abstract].

[44] J. W. Aaronson, C. L. Murphy-Cullen, W. M. Chop, R. D. Frey. Electronic medical records: the family practice resident perspective. Fam Med. 2001; 33(2):128-32.

[45] A. L Terry, C. F. Thorpe, G. Giles, et al. Implementing electronic health records. Can Fam Physician. 2008 May; 54(5): 730-736. PMCID: PMC2377228.

[46] K. H. Damsky, L. D. Gamm, J. J. Vasey, C. K. Barsukiewicz. Electronic medical records: are physicians ready? J Healthcare Manag. 1999;44(6):440-54.

[47] S. H. Houser, L. A. Johnson. Perceptions regarding electronic health record implementation among health information management professionals in Alabama: a statewide survey and analysis. Perspectives in Health Information Management. 2008;5(6):1-15.

[48] The Consumer-Purchaser Disclosure Project. Meaningful Use of Health Information Technology What It Is and Why It Matters to Patients and Purchasers, 2010. Available at www.healthcarediclosure.org. Accessed on November 18, 2014. 